\title{
IDENTIFIKASI JENIS TANAMAN HUTAN RAKYAT DAN PEMELIHARAANNYA DI HUTAN RAKYAT DESA KELUNGU KECAMATAN KOTAAGUNG KABUPATEN TANGGAMUS
}

\section{THE IDENTIFICATION AND MAINTENANCE OF SOCIAL FOREST PLANT SPECIES IN KELUNGU VILLAGE KOTAAGUNG SUB-DISTRICT TANGGAMUS REGENCY}

Oleh :

Endang S. Oktaviyani, Indriyanto, Surnayanti

Jurusan Kehutanan Fakultas Pertanian Universitas Lampung

J1. Soemantri Brojonegoro No. 1 Bandar Lampung 35143

Email: endangoktaviyani@gmail.com

No. Handphone : +628971776123

\begin{abstract}
ABSTRAK
Alih-guna lahan hutan rakyat menjadi lahan pertanian menjadi sumber dari masalah penurunan kesuburan tanah, erosi, banjir, kekeringan bahkan menimbulkan perubahan lingkungan global. Agroforestri merupakan salah satu sistem pengelolaan lahan yang dapat dijadikan alternatif untuk mengatasi masalah yang timbul akibat adanya alih-guna lahan hutan dan sekaligus untuk mengatasi masalah pangan.

Penelitian ini bertujuan untuk mengetahui jenis tanaman pada hutan rakyat di Desa Kelungu Kecamatan Kotaagung Kabupaten Tanggamus Mengetahui kegiatan pemeliharaan tanaman pada agroforestri hutan rakyat di Desa Kelungu Kecamatan Kotaagung Kabupaten Tanggamus. Penelitian ini dilakukan selama Bulan September sampai dengan Oktober 2015 bertempat di lahan Hutan Rakyat Desa Kelungu, Kecamatan Kotaagung, Kabupaten Tanggamus. Analisis yang digunakan berupa kerapatan setiap populasi tanaman.

Hasil penelitian menunjukkan bahwa ditemukan 22 spesies, dengan kerapatan tertinggi yaitu Kakao (Theobrema cacao) sebesar 529,17 individu/ha. Untuk fase pohon, kerapatan tertinggi ditempati oleh Durian (Durio zibethinus) yaitu sebesar 73,61 individu/ha.

Kegiatan pemeliharaan yang dilakukan oleh petani Di Desa Kelungu meliputi pemupukan, penyulaman, pendangiran, penyiangan gulma, pemangkasan cabang, pewiwilan, penjarangan, pengendalian hama penyakit. Dari 36 petani $60 \%$ diantaranya melakukan pemupukan. $77 \%$ melakukan penyulaman, $77 \%$ melakukan pendangiran, $100 \%$ melakukan penyiangan gulma, 93\% melakukan pemangkasan cabang, 83\% melakukan pewiwilan, 7\% melakukan penjarangan, dan $57 \%$ melakukan pengendalian hama penyakit tanaman
\end{abstract}

\section{ABSTRACT}

Land-use change into field becomes main problems namely soil fertility degradation, erosion, flood, drought, not to mention global environment changes. Agroforestry is one of the land management system that could be used as an alternative to overcome the problems that arise due to land-use change as well as to overcome the food problem.

The purpose of this study were to determine the social forest plant species on Kelungu village of Kotaagung sub-district, Tanggamus Regency Knowing the plants maintenance activities on social forests in Kelungu village of Kotaagung sub-district, Tanggamus Regency. This research was conducted from September to October 2015 that was located in social forest areas of Kelungu village, Kotaagung Sub-district, Tanggamus Regency. The analysis that used was the density.

The results showed that about 22 species founded, with the highest density of cacao (Cacao theobrema) about 529.17 individuals/ha. the highest density of trees phase is durian 
(Durio zibethinus) about 73.61 individuals/ha. Maintenance activities carried out by the farmers in the Kelungu Village were fertilizing, replanting, soil loosening, weeding, branches and buds prunning, thinning, pest and disease control. From 36 farmers has done much treatment, there were $60 \%$ fertilizing, $77 \%$ replanting, $77 \%$ loosening, $100 \%$ do weeding, 93\% branches prunning, 83\% bud prunning, 7\% thinning, and 57\% pest and disease control treatments.

\section{PENDAHULUAN}

Sumber daya alam merupakan segala sesuatu yang ada di alam yang dapat digunakan manusia untuk memenuhi kebutuhannya, salah satu sumber daya alam yaitu sumber daya hutan, hutan merupakan suatu ekosistem alamiah yang sangat kompleks dan mengandung sangat banyak jenis pepohonan, mulai dari pohon yang kecil sampai ke pohon-pohon raksasa maupun juga tumbuhan pakis, lumut dan jamur yang kemudian juga menjadi habitat bagi kehidupan berbagai jenis hewan dan jasad renik (Indriyanto, 2008).

Secara kepemilikan, hutan dibagi menjadi dua yaitu hutan negara dan hutan hak, dimana hutan rakyat masuk kedalam hutan hak (UU No. 41 Tahun 1999). Menurut Hardjosoediro (1980) yang dikutip Mahendra (2009) hutan rakyat atau hutan milik adalah semua hutan yang ada di Indonesia yang tidak berada di atas tanah yang tidak dikuasai pemerintah, hutan yang dimiliki rakyat. Dalam pengolahan hutan rakyat, pemilihan jenis tanamannya kurang diperhatikan, karena mayoritas petani lebih memaksimalkan hasil panen dan kurang memperhatikan aspek ekologis dari pengelolaan lahan hutan rakyat tersebut. Hal ini membuat lahan hutan menjadi semakin tertekan.

Ketergantungan masyarakat sekitar hutan terhadap sumber daya hutan guna memenuhi kebutuhan hidupnya merupakan penyebab adanya tekanan terhadap kawasan hutan. Lahan yang awalnya adalah kawasan hutan di konversi menjadi lahan pertanian, perkebunan serta pemukiman tanpa memperhatikan kelestariannya. Alih-guna lahan hutan menjadi lahan pertanian menjadi sumber dari masalah penurunan kesuburan tanah, erosi, banjir, kekeringan bahkan menimbulkan perubahan lingkungan global.

Agroforestri merupakan salah satu sistem pengelolaan lahan yang dapat dijadikan alternatif untuk mengatasi masalah yang timbul akibat adanya alih-guna lahan hutan dan sekaligus untuk mengatasi masalah pangan. Agroforestri penting untuk diterapkan karena sistem ini bertujuan mempertahankan atau meningatkan hasil dengan efektif. Selain itu sistem agroforestri juga bermanfaat untuk memperbaiki kondisi ekologis di suatu lahan. Salah satu teknik agroforestri yang bisa dilakukan adalah dengan menanami suatu lahan dengan menggabungkan antara tumbuhan berkayu (tanaman hutan) dengan tanaman pangan atau pakan ternak (Sardjono dkk., 2003).

Masyarakat Desa Kelungu, Kecamatan Kotaagung menerapakan sistem agroforestri dalam pengelolaan lahannya. Jenis-jenis tanaman yang pada umumnya ditanam petani sebagai hutan rakyat yaitu sengon, durian, manggis, dan duku. Namun dalam pengelolaannya, belum diketahui secara menyeluruh terkait jenis-jenis tanamannya dan bagaimana kegiatan pemeliharaannya sehingga perlu diadakan penelitian terkait jenis tanaman agroforestri dan pemeliharaannya di Hutan Rakyat Desa Kelungu, Kecamatan Kotaagung, Kabupaten Tanggamus. Dengan adanya data tersebut dapat dijadikan informasi bagi masyarakat, pemerintah, dan instansi terkait jenis tanaman agroforestri dan pemeliharaan tanaman pada desa tersebut sehingga dapat dijadikan acuan dalam pengelolaan lahan secara berkelanjutan. Penelitian ini bertujuan untuk mengetahui jenis tanaman agroforestri pada hutan rakyat dan mengetahui kegiatan pemeliharaan tanaman pada agroforestri hutan rakyat di Desa Kelungu Kecamatan Kotaagung Kabupaten Tanggamus. 


\section{METODE PENELITIAN}

\section{A. Lokasi dan Waktu Penelitian}

Penelitian ini dilakukan selama Bulan September sampai dengan Oktober 2015 bertempat di lahan Hutan Rakyat Desa Kelungu, Kecamatan Kotaagung, Kabupaten Tanggamus.

\section{B. Data yang Dikumpulkan}

Jenis data yang dikumpulkan dalam penelitian ini meliputi data primer dan data sekunder. Pengumpulan data primer akan dilakukan dengan metode observasi dan wawancara. Observasi dilakukan untuk mengambil data vegetasi yang meliputi jenis tanaman, dan jumlah individu tiap jenis yang ada dilahan pemilik hutan rakyat. Sedangkan wawancara dilakukan langsung dengan responden melalui tanya jawab menggunakan daftar pertanyaan atau kuesioner. Pengumpulan data sekunder dilakukan dengan mengutip data hasil publikasi yang diperlukan dan sesuai dengan penelitian. Selain itu data juga akan diambil dari instansi terkait seperti dinas kehutanan, kantor kelurahan setempat, dan data lain yang relevan dengan penelitian.

Penentuan responden petani hutan rakyat Desa Kelungu Kecamatan Kotaagung Kabupaten Tanggamus yang dilakukan dalam penelitian ini akan ditentukan dengan metode sensus. Sensus penduduk merupakan salah satu teknik penentuan responden yang dipilih karena jumlah dari populasi yang ada kurang dari 100 orang.Populasi petani hutan rakyat yang terdapat di Desa Kelungu Kecamatan Kotaagung Kabupaten Tanggamus berjumlah 30 KK.Dengan demikian jumlah responden pada penelitian ini adalah keseluruhannya yaitu 30 orang responden. Menurut Arikunto (2002):

1. Jika subjek $>100$ orang, sampel yang diambil 10\%--15\% dari total subjek.

2. Jika subjek $<100$ orang, sampel yang diambil keseluruhan dari subjek yang ada atau sensus.

Setelah memperoleh sampel responden, maka selanjutnya adalah menentukan sampel vegetasi dengan melakukan pengamatan terhadap komposisi jenis tanaman tanaman dengan metode analisis vegetasi. Analisis vegetasi dilakukan dengan membuat satu plot persegi pada setiap lahan pemilik hutan rakyat di Desa Kelungu yang menjadi responden. Adapun cara pembuatan plot persegi ialah sebagai berikut.

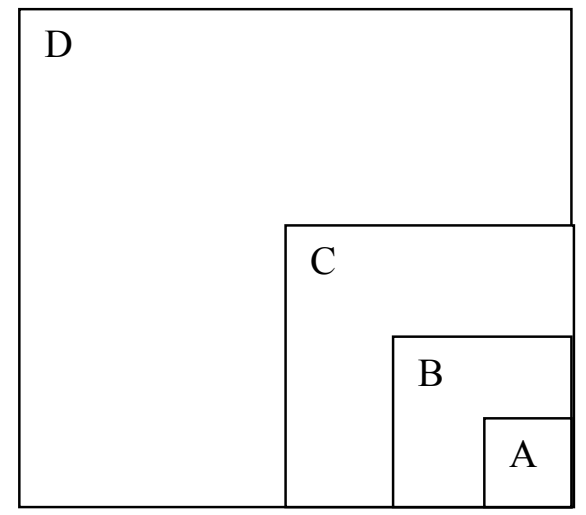

Gambar 2. Petak contoh persegi yang dibuat pada lahan hutan rakyat di Desa Kelungu untuk menghimpun data vegetasi hutan rakyat. 
Keterangan.

1. A merupakan petak contoh berukuran $2 \mathrm{~m} \times 2 \mathrm{~m}$ digunakan untuk tingkat semai dengan tinggi tumbuhan $<1,5 \mathrm{~m}$ dan untuk tumbuhan bawah.

2. B merupakan petak contoh ukuran $5 \mathrm{~m} \times 5 \mathrm{~m}$ digunakan untuk tingkat pancang dengan diameternya $<10 \mathrm{~cm}$ dan tinggi tanmannya $>1,5 \mathrm{~m}$.

3. C merupakan petak contoh ukuran $10 \mathrm{~m} \times 10 \mathrm{~m}$ digunakan untuk tingkat tiang dengan diameternya $10--20 \mathrm{~cm}$.

4. D merupakan petak contoh ukuran $20 \mathrm{~m}$ x $20 \mathrm{~m}$ digunakan untuk tingkat pohon dengan diameter $>20 \mathrm{~cm}$.

\section{Analisis dan Penyajian Data}

Data kerapatan pohon mengenai jumlah dan jenis tanaman yang diperoleh dianalisis secara kuantitatif menggunakan rumus kerapatan pohon yang didasarkan pada perhitungan nilai kerapatan serta dideskripsikan.Menurut Indriyanto (2008) kerapatan dirumuskan dengan rumus sebagai berikut.

$$
\text { Kerapatan }(\mathrm{K})=\frac{\text { Jumlah Individu Suatu Jenis }}{\text { Luas Petak Contoh }}
$$

Data jenis tanaman, kerapatan $(\mathrm{K})$, cara pengaturan letak tanaman, data tentang kegiatan pemeliharaan, dan data tentang dimensi tegakan ditabulasikan dalam bentuk tabel.

\section{HASIL DAN PEMBAHASAN}

\section{Bentuk dan Komposisi Hutan Rakyat}

Hutan rakyat di Desa Kelungu dikelola secara perorangan oleh masing-masing petani pemilik lahan dengan sistem agroforestri. Hutan rakyat yang dikembangkan dengan pola agroforestri akan memberikan hasil tidak hanya kayu saja melainkan juga buah-buahan, pangan, obat-obatan, bambu, tanaman industri dan lain sebagainya (Diniyati dan Budiman, 2015).

Sistem agroforestri yang diterapkan pada lahan hutan rakyat tersebut menggabungkan komponen pertanian dan komponen kehutanan sehingga diperoleh kompisisi jenis tanaman yang cukup beragam. Komposisi jenis tanaman pada hutan rakyat di Desa Kelungu disajikan pada Tabel 5.

Tabel 5.Jenis pohon dan perdu yang ditanam masyarakat di hutan rakyat Desa Kelungu

Kecamatan Kotaagung.

\begin{tabular}{cll}
\hline No. & \multicolumn{1}{c}{ Nama Lokal } & \multicolumn{1}{c}{ Nama Ilmiah } \\
\hline 1 & Alpukat & Persea Americana \\
2 & Cempaka & Michelia campacca \\
3 & Cengkeh & Eugenia aromaticum \\
4 & Dadap & Erythrina variegate \\
5 & Duku & Lansium domesticum \\
6 & Durian & Durio zibethinus \\
7 & Jambu Bol & Syzygium malasccence \\
8 & Jati & Tectona grandis \\
9 & Jengkol & Pithesellobium lobatum \\
10 & Kakao & Theobrema cacao \\
11 & Kelapa & Coconus nucifera \\
12 & K.emiri & Aleurites moluccanus \\
13 & Ketapang & Terminalia catappa \\
\hline
\end{tabular}




\begin{tabular}{lll}
\hline 14 & Ketupak & Baccaurea dulcis \\
15 & Kopi & Coffea Arabica \\
16 & Mahoni & Swietenia macrophylla \\
17 & Mangga & Mangifera indica \\
18 & Manggis & Garcinia mangostana \\
19 & Medang & Dehaasia cuneta \\
20 & Melinjo & Gnetum gnemon \\
21 & Merambung & Peronema arborea \\
22 & Nangka & Artocarpus heterophyllu \\
23 & Pala & Myristica fragrance \\
24 & Petai & Parkia speciosa \\
25 & Pinang & Pinanga sp. \\
26 & Rambutan & Nephellium lapaceum \\
27 & Randu & Ceiba pentandra \\
28 & Salam & Eugenia polyantha \\
29 & Sengon & Enterolobyum cyclocarpum \\
\hline
\end{tabular}

Jenis tanaman yang terdapat pada hutan rakyat di Desa Kelungu terdiri dari jenis tanaman berkayu, tanaman MPTS dan tanaman perkebunan. Jenis tanaman berkayu yang terdapat di hutan rakyat Desa Kelungu antara lain Cempaka, Jati, Ketapang, Mahoni, Merambung. Jenis tanaman MPTS yang terdapat pada hutan rakyat di Desa Kelungu antara lain Alpukat, Duku, Durian, Jambu Bol, Jengkol, Kemiri, Ketupak, Mangga, Manggis, Melinjo, dan Nangka. Sedangkan tanaman perkebunan yang terdapat pada hutan rakyat di Desa Kelungu yaitu Kakao, Kopi dan Cengkeh.

\section{Kerapatan Jenis Pohon}

Hutan rakyat di Desa Kelungu terdiri dari tanaman dengan beberapa fase pertumbuhan yang meliputi fase semai, pancang, tiang hingga pohon.Kerapatan/ha masingmasing tanaman pada fase semai, pancang, tiang dan pohon disajikan pada Tabel 2.

Tabel 2. Kerapatan setiap populasi jenis pohon dan perdu setiap fase pertumbuhan di hutan rakyat Desa Kelungu Kecamatan Kotaagung

\begin{tabular}{lrrrrr}
\hline \multirow{2}{*}{ Jenis } & \multicolumn{5}{c}{ Kerapatan Per Ha } \\
\cline { 2 - 6 } Alpukat & Pohon & \multicolumn{1}{c}{ Tiang } & Pancang & Semai & Jumlah \\
\hline Cempaka & 4.17 & 0.00 & 0.00 & 0.00 & 4.17 \\
\hline Cengkeh & 25.00 & 16.67 & 11.11 & 0.00 & 52.78 \\
\hline Dadap & 0.00 & 47.22 & 0.00 & 0.00 & 47.22 \\
\hline Duku & 0.69 & 0.00 & 0.00 & 0.00 & 0.69 \\
\hline Durian & 11.81 & 2.78 & 11.11 & 0.00 & 25.69 \\
\hline Jambu Bol & 54.17 & 8.33 & 11.11 & 0.00 & 73.61 \\
\hline Jati & 0.00 & 0.00 & 11.11 & 0.00 & 11.11 \\
\hline Jengkol & 22.22 & 0.00 & 0.00 & 0.00 & 22.22 \\
\hline Kakao & 4.86 & 8.33 & 33.33 & 138.89 & 185.42 \\
\hline Kelapa & 4.17 & 358.33 & 166.67 & 0.00 & 529.17 \\
\hline Kemiri & 16.67 & 0.00 & 0.00 & 0.00 & 16.67 \\
\hline Ketapang & 2.08 & 0.00 & 0.00 & 0.00 & 2.08 \\
\hline Ketupak & 1.39 & 0.00 & 0.00 & 0.00 & 1.39 \\
\hline Kopi & 0.00 & 8.33 & 0.00 & 0.00 & 8.33 \\
\hline Mahoni & 0.00 & 0.00 & 44.44 & 0.00 & 44.44 \\
\hline
\end{tabular}




\begin{tabular}{lrrrrr}
\hline Mangga & 0.69 & 0.00 & 0.00 & 0.00 & 0.69 \\
\hline Manggis & 5.56 & 0.00 & 33.33 & 0.00 & 38.89 \\
\hline Melinjo & 0.00 & 5.56 & 33.33 & 69.44 & 108.33 \\
\hline Merambung & 2.08 & 8.33 & 0.00 & 0.00 & 10.42 \\
\hline Nangka & 1.39 & 0.00 & 0.00 & 0.00 & 1.39 \\
\hline Pala & 0.00 & 0.00 & 22.22 & 0.00 & 22.22 \\
\hline Petai & 13.19 & 0.00 & 0.00 & 0.00 & 13.19 \\
\hline Pinang & 0.00 & 2.78 & 0.00 & 0.00 & 2.78 \\
\hline Rambutan & 2.08 & 0.00 & 0.00 & 0.00 & 2.08 \\
\hline Randu & 0.69 & 0.00 & 0.00 & 0.00 & 0.69 \\
\hline Salam & 0.00 & 0.00 & 11.11 & 0.00 & 11.11 \\
\hline Sengon & 4.86 & 11.11 & 300.00 & 0.00 & 315.97 \\
\hline Jumlah & $\mathbf{1 7 8 . 4 7}$ & $\mathbf{4 8 6 . 1 1}$ & $\mathbf{6 8 8 . 8 9}$ & $\mathbf{2 0 8 . 3 3}$ & $\mathbf{1 5 6 4 . 5 8}$ \\
\hline
\end{tabular}

Berdasarkan Tabel 2 terlihat bahwa tanaman yang paling tinggi kerapatannya secara keseluruhan yaitu tanaman kakao (Theobrema cacao). Berbeda dengan Penelitian yang dilakukan oleh Rizal.,dkk (2012) pada hutan rakyat di dua kabupaten di Sulawesi Selatan menunjukkan kabupaten Barru kerapatan tertinggi yaitu tanaman jati. Kakao merupakan salah satu komoditas perkebunan yang berperan penting bagi pertumbuhan perekonomian Indonesia terutama dalam penyediaan lapangan kerja baru, sumber pendapatan petani dan penghasil devisa bagi negara.

Tanaman kakao banyak dibudidayakan di Desa Kelungu karena memiliki nilai ekonomis yang cukup tinggi. Pada hutan rakyat di Desa Kelungu tanaman kakao banyak di tumpang sarikan dengan tanaman lain seperti durian, petai, jengkol, sengon, dan lain-lain. Menurut A.A. Prawoto (2008) tanaman yang menunjukan kombinasi paling baik dengan kakao adalah tanaman kelapa, hal ini disebabkan tanaman kelapa merupakan tanaman pematah angin yang efektif dan pada tanaman kelapa yang sudah dewasa akan menciptakan jarak yang cukup lebar antar tajuk sehingga menciptakan sirkulasi udara yang baik dan membantu sanitasi kebun.

Kombinasi tanaman tersebut tidak diterapkan pada hutan rakyat di Desa Kelungu. Petani di desa tersebut lebih banyak mengkombinasikan tanaman kakao dengan tanaman durian sehingga durian memiliki kerapatan tertinggi yaitu sebesar 54,16 individu/ha. Petani hutan rakyat pada Desa Kelumgu banyak memilih tanaman durian karena durian memiliki nilai ekonomi yang cukup tinggi dan dapat tumbuh dengan baik pada daerah tersebut.

Selain itu Pengembangan budidaya durian paling baik dilakukan di daerah dataran rendah sampai ketinggian 800 meter di atas permukaan laut dan keadaan iklim basah, suhu udara antara $250-320^{\circ} \mathrm{C}$ (Rukmana, 1996). Hal ini sesuai dengan daerah Kabupaten Tanggamus secara umum yaitu memiliki temperatur udara rata-rata $28^{\circ}$ Celcius dan sebagian wilayah dengan udara sejuk pegunungan yang terletak sekitar $500 \mathrm{~m}$ dpl sampai dengan 2000 meter dpl di kaki Gunung Tanggamus (Badan Perencanaan dan Pembangunan Daerah Kabupaten Tanggamus, 2013). Nilai ekonomi yang cukup tinggi dan kesesuaian tempat tumbuh yang memungkinkan untuk pohon durian tumbuh dengan subur membuat petani tertarik untuk menanam durian.

Fase semai yang ditemukan pada plot pengamatan hanya terdapat 2 jenis yaitu jengkol dan melinjo. Fase semai jarang dijumpai karena tingkat kerapatan dari pohon dan tiang dilahan petani sudah cukup tinggi sehingga tidak memungkinkan untuk semai dapat tumbuh dengan baik.Selain itu petani tidak membiarkan semai untuk hidup, petani cenderung membersihkan semai yang tumbuh pada saat kegiatan pemeliharaan penyiangan gulma. 


\section{Kegiatan Pemeliharaan}

Kegiatan pemeliharaan merupakan kegiatan yang dilakukan masyarakat pengelola hutanrakyat untuk memelihara tanaman miliknya sehingga tanaman tersebut dapat tumbuh denganbaik dan memberikan hasil yang maksimal (Simon,2004).Petani Desa Kelungu juga melakukan kegiatan pemeliharaan tanaman yang dibudidayakan pada lahan kebun mereka, kegiatan pemeliharaan tanaman di hutan rakyat Desa Kelungu dilakukan tidak pada semua tanaman. Petani di Desa Kelungu cenderung memelihara kakao secara intensif dibandingkan dengan tanaman lainnya yang ada pada lahan mereka, karena memang tanaman pokok para petani di desa ini adalah tanaman kakao.

Data lengkap tentang berbagai aspek pemeliharaan tanaman yang dilakukan oleh masyarakat desa Kelungu Kecamatan Kotaagung di tiap jenis tanaman yang dibudidayakan disajikan dalam tabel 3 di bawah ini. 


\section{Jurnal Sylva Lestari}

Vol. 5 No.2, April 2017 (63-77)
ISSN (print) 2339-0913

ISSN (online) 2549-5747

Tabel 3.Persentase jumlah petani yang melakukan berbagai aspek pemeliharaan terhadap jenis-jenis tanaman yang di budidayakan.

\begin{tabular}{|c|c|c|c|c|c|c|c|c|c|}
\hline No & $\begin{array}{c}\text { Jenis } \\
\text { Tanaman }\end{array}$ & Pemupukan & Penyulaman & Pendangiran & $\begin{array}{c}\text { Penyiangan } \\
\text { gulma }\end{array}$ & $\begin{array}{c}\text { Pemangkasan } \\
\text { cabang }\end{array}$ & Pewiwilan & Penjarangan & $\begin{array}{c}\text { Pengendalian } \\
\text { hama penyakit }\end{array}$ \\
\hline 1 & Alpukat & $0 \%$ & $0 \%$ & $0 \%$ & $100 \%$ & $0 \%$ & $0 \%$ & $0 \%$ & $0 \%$ \\
\hline 2 & Cempaka & $6 \%$ & $65 \%$ & $41 \%$ & $100 \%$ & $53 \%$ & $6 \%$ & $0 \%$ & $0 \%$ \\
\hline 3 & Cengkeh & $50 \%$ & $50 \%$ & $50 \%$ & $100 \%$ & $50 \%$ & $0 \%$ & $0 \%$ & $0 \%$ \\
\hline 4 & Dadap & $0 \%$ & $0 \%$ & $0 \%$ & $100 \%$ & $0 \%$ & $0 \%$ & $0 \%$ & $0 \%$ \\
\hline 5 & Duku & $0 \%$ & $8 \%$ & $8 \%$ & $100 \%$ & $0 \%$ & $8 \%$ & $0 \%$ & $0 \%$ \\
\hline 6 & Durian & $12 \%$ & $15 \%$ & $12 \%$ & $100 \%$ & $0 \%$ & $4 \%$ & $0 \%$ & $0 \%$ \\
\hline 7 & Jambu Bol & $0 \%$ & $0 \%$ & $0 \%$ & $100 \%$ & $0 \%$ & $0 \%$ & $0 \%$ & $0 \%$ \\
\hline 8 & Jati & $0 \%$ & $100 \%$ & $100 \%$ & $100 \%$ & $100 \%$ & $0 \%$ & $0 \%$ & $0 \%$ \\
\hline 9 & Jengkol & $0 \%$ & $14 \%$ & $0 \%$ & $100 \%$ & $0 \%$ & $0 \%$ & $0 \%$ & $0 \%$ \\
\hline 10 & Kakao & $58 \%$ & $67 \%$ & $75 \%$ & $100 \%$ & $100 \%$ & $100 \%$ & $4 \%$ & $54 \%$ \\
\hline 11 & Ketapang & $0 \%$ & $0 \%$ & $0 \%$ & $100 \%$ & $0 \%$ & $0 \%$ & $0 \%$ & $0 \%$ \\
\hline 12 & Kelapa & $0 \%$ & $0 \%$ & $0 \%$ & $100 \%$ & $0 \%$ & $0 \%$ & $0 \%$ & $0 \%$ \\
\hline 13 & Kemiri & $0 \%$ & $100 \%$ & $0 \%$ & $100 \%$ & $0 \%$ & $0 \%$ & $0 \%$ & $0 \%$ \\
\hline 14 & Ketupak & $0 \%$ & $0 \%$ & $0 \%$ & $100 \%$ & $0 \%$ & $0 \%$ & $0 \%$ & $0 \%$ \\
\hline 15 & Kopi & $100 \%$ & $100 \%$ & $100 \%$ & $100 \%$ & $100 \%$ & $100 \%$ & $0 \%$ & $0 \%$ \\
\hline 16 & Mahoni & $0 \%$ & $0 \%$ & $0 \%$ & $100 \%$ & $0 \%$ & $0 \%$ & $0 \%$ & $0 \%$ \\
\hline 17 & Mangga & $0 \%$ & $0 \%$ & $0 \%$ & $100 \%$ & $0 \%$ & $0 \%$ & $0 \%$ & $0 \%$ \\
\hline 18 & Manggis & $0 \%$ & $0 \%$ & $0 \%$ & $100 \%$ & $0 \%$ & $0 \%$ & $0 \%$ & $0 \%$ \\
\hline 19 & Medang & $0 \%$ & $0 \%$ & $0 \%$ & $100 \%$ & $0 \%$ & $0 \%$ & $0 \%$ & $0 \%$ \\
\hline 20 & Melinjo & $0 \%$ & $0 \%$ & $0 \%$ & $100 \%$ & $0 \%$ & $0 \%$ & $0 \%$ & $0 \%$ \\
\hline 21 & Merambung & $0 \%$ & $0 \%$ & $0 \%$ & $100 \%$ & $0 \%$ & $0 \%$ & $0 \%$ & $0 \%$ \\
\hline 22 & Nangka & $0 \%$ & $0 \%$ & $0 \%$ & $100 \%$ & $0 \%$ & $0 \%$ & $0 \%$ & $0 \%$ \\
\hline 23 & Pala & $0 \%$ & $0 \%$ & $0 \%$ & $100 \%$ & $0 \%$ & $0 \%$ & $0 \%$ & $0 \%$ \\
\hline
\end{tabular}




\section{Jurnal Sylva Lestari}

Vol. 5 No.2, April 2017 (63-77)
ISSN (print) 2339-0913

ISSN (online) 2549-5747

\begin{tabular}{|c|c|c|c|c|c|c|c|c|c|}
\hline No & Jenis Tanaman & Pemupukan & Penyulaman & Pendangiran & $\begin{array}{c}\text { Penyiangan } \\
\text { gulma }\end{array}$ & $\begin{array}{c}\text { Pemangkasan } \\
\text { cabang }\end{array}$ & Pewiwilan & Penjarangan & $\begin{array}{c}\text { Pengendalian } \\
\text { hama penyakit }\end{array}$ \\
\hline 24 & Petai & $0 \%$ & $0 \%$ & $9 \%$ & $100 \%$ & $0 \%$ & $9 \%$ & $0 \%$ & $0 \%$ \\
\hline 25 & Pinang & $0 \%$ & $0 \%$ & $0 \%$ & $100 \%$ & $0 \%$ & $0 \%$ & $0 \%$ & $0 \%$ \\
\hline 26 & Rambutan & $0 \%$ & $0 \%$ & $0 \%$ & $100 \%$ & $0 \%$ & $0 \%$ & $0 \%$ & $0 \%$ \\
\hline 27 & Randu & $0 \%$ & $0 \%$ & $0 \%$ & $100 \%$ & $0 \%$ & $0 \%$ & $0 \%$ & $0 \%$ \\
\hline 28 & Salam & $0 \%$ & $0 \%$ & $0 \%$ & $100 \%$ & $0 \%$ & $0 \%$ & $0 \%$ & $0 \%$ \\
\hline 29 & Sengon & $30 \%$ & $80 \%$ & $40 \%$ & $100 \%$ & $60 \%$ & $0 \%$ & $10 \%$ & $0 \%$ \\
\hline
\end{tabular}


Dari Tabel 3 di atas dapat dilihat bahwa tanaman yang banyak dipelihara secara intensif pada hutan rakyat di Pekon Kelungu yaitu kakao, kopi dan jati. Hal ini disebabkan karena masyarakat berasumsi bahwa tanaman tersebut merupakan tanaman yang perlu dipelihara secara intensif agar mendapatkan hasil yang maksimal. Sedangkan jenis tanaman lain seperti cempaka, durian,dan duku pada hutan rakyat di Desa Kelungu tidak dipelihara secara intensif. Hal tersebut dikarenakan asumsi masyarakat bahwa tanaman-tanaman yang kurang dipelihara itu adalah tanaman yang dapat bertahan hidup meski kurang dipelihara, dan tidak begitu berpengaruh dalam peningkatan hasil meskipun dilakukan pemeliharaan.

Penelitian Wijayanto dan Hartoyo (2015) di Krui Lampung tanaman yang biasanya diberi pupuk adalah teh, cengkeh, pisang, kapol, kelapa, melinjo, manggis dan pala. Pupuk yang diberikan adalah pupuk kandang atau pupuk urea. Kegiatan pemupukan dilakukan hanya pada $45,71 \%$ responden karena sebagian petani beranggapan bahwa kebun mereka memiliki kondisi tanah yang subur dan pembusukan serasah-serasah daun yang berjatuhan sudah cukup untuk memberikan tambahan hara.

Kegiatan pemeliharaan tanaman yang ada di hutan rakyat Desa Kelungu berupa pemupukan, penyulaman, pendangiran, penyiangan gulma, pemangkasan cabang, pewiwilan, penjarangan, dan pengendalian hama penyakit. Kegiatan ini sama hal nya dengan kegiatan pemeliharaan menurut Kementerian Kehutanan (2012). Sedikit berbeda dengan kegiatan pemeliharaan yang dilakukan petani hutan rakyat di Desa Bandar Dalam Kecamatan Sido Mulyo Kabupaten Lampung Selatan yaitu berupa penyiangan, pemupukan, pemangkasan cabang, penjarangan, pemberantasan hama dan penyakit (Pratama dkk,. 2015).

Persentase petani yang yang melakukan pemeliharan tanaman pada lahan hutan rakyat di Desa Kelungu Kecamatan Kotaagung Kabupaten Tanggamus disajikan dalam bentuk grafik sebagai berikut.

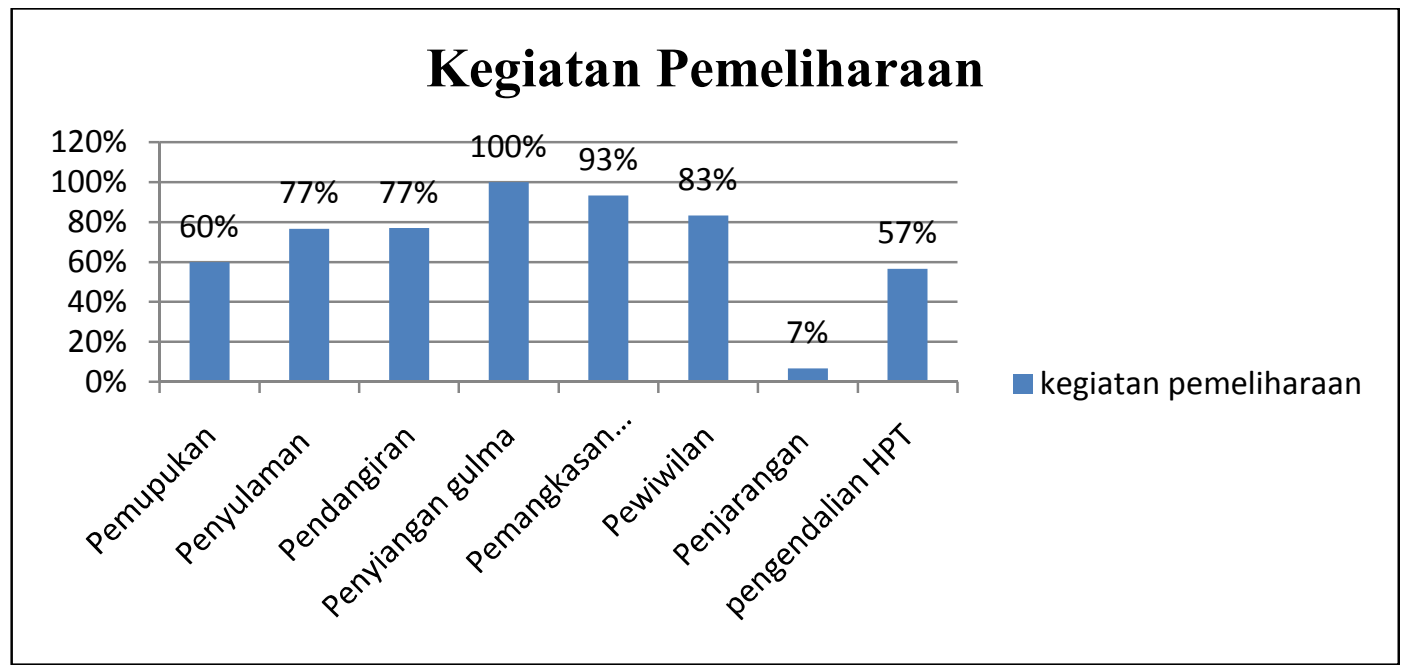

Gambar 3.Grafik persentase kegiatan pemeliharaan tanaman yang dilakukan oleh petani Di Hutan Rakyat Desa Kelungu.

Pemeliharaan yang paling banyak dilakukan oleh petani di Desa Kelungu adalah penyiangan gulma, hal ini disebabkan karena penyiangan gulma merupakan kegiatan yang mudah untuk dilakukan, selain itu masyarakat petani di Desa Kelungu memiliki suatu prinsip bahwa kebersihan dari lahan kebun adalah suatu tolak ukur dalam kesungguhan menggarap lahan kebun. Sedangakan pemeliharaan yang paling sedikit dilakukan adalah penjarangan tanaman, hal ini 
dikarenakan penjarangan hanya dilakukan pada tanaman yang menghasilkan kayu seperti cempaka dan sengon sedangkan masyarakat petani lebih banyak menanam tanaman perkebunan seperti kakao dan pohon-pohon MPTS.

Berikut adalah uraian dari kegiatan pemeliharaan yang dilakukan oleh petani di Desa Kelungu.

\section{a. Pemupukan}

Petani melakukan pemupukan agar tanaman mereka menjadi lebih meningkat produktivitasnya meskipun ada juga yang berasumsi bahwa pemupukan bukan sesuatu yang begitu penting untuk dilakukan. Sebanyak $60 \%$ dari masyarakat petani melakukan pemupukan pada tanaman yang ada dilahan kebun mereka. Dalam kegiatan pemupukan, jenis pupuk yang digunakan oleh petani berbeda-beda dan dari 60\% yang melakukan pemupukan, $83 \%$ diantaranya menggunakan pupuk NPK dengan dosis $1 / 4 \mathrm{~kg}$ per pohon, $11 \%$ menggunakan pupuk NPK+urea dengan perbandingan 50/50 dan 6\% menggunakan pupuk urea. Petani banyak yang menggunakan pupuk urea dan NPK karena menurut mereka selain harganya terjangkau, kedua pupuk ini yang paling mudah didapat dipasaran.

Waktu pemupukan petani relatif sama yaitu ketika musim penghujan dan di akhir musim penghujan, karena pada saat-saat ini pupuk akan cepat larut kedalam tanah. Hal ini sesuai menurut waktu ideal pemupukan menurut Pujiyanto (2008) yaitu pada saat musim penghujan atau akhir musim penghujan (Maret-April atau Oktober-November). Pujiyanto (2008) juga mengungkapkan terkait aplikasi pemupukan yang baik yakni dengan cara meletakkan pupuk pada parit melingkar disekitar pohon lalu menutupnya kembali dengan tanah. Hal ini juga yang diterapkan para petani Desa Kelungu dalam aplikasi pemupukan pada lahan kebun mereka.

\section{b. Penyulaman}

Penyulaman adalah kegiatan penanaman kembali bagian-bagian yang kosong bekas tanaman mati/akan mati dan rusak sehingga jumlah tanaman normal dalam satu kesatuanluas tertentu sesuai dengan jarak tanamnya.Penyulaman bertujuan untuk meningkatkan persen jadi tanaman dalam satu kesatuan luas tertentu sehingga memenuhi jumlah yang diharapkan (Kementrian Kehutanan, 2012).

Sebanyak 77\% masyarakat petani melakukan kegiatan penyulaman, kegiatan penyulaman yang dilakukan oleh petani yaitu mengganti tanaman yang mati dengan tanaman yang baru, dan kegiatan ini hanya dilakukan jika ada tanaman yang mati pada saat awal penanaman, waktu dari kegiatan penyulaman ini tidak menentu karena kegiatan ini dilakukan hanya ketika perlu untuk mengganti tanaman mati dengan tanaman yag baru. Masyarakat mendapatkan bibit untuk penyulaman dengan membeli.

\section{c. Pendangiran}

Pendangiran adalah kegiatan penggemburan tanah disekitar tanaman pokok yang bertujuan untuk memperbaiki sifat fisik tanah (aerasi tanah) sebagai upaya memacupertumbuhan tanaman. Waktu pendangiran dilakukan pada musim kemarau menjelang musim hujan tiba (Kementrian Kehutanan, 2012).

77\% dari petani melakukan kegiatan pendangiran, waktu kegiatan pendangiran relatif berbeda antara petani satu dengan petani lainnya mulai dari kurun waktu 1 bulan sampai 1 tahun sekali, pendangiran atau dalam bahasa setempat membuat angin-anginan, dilakukan dengan cara mencangkul tanah disekitar tanaman untuk meningkatan kesuburan tanah.

Menurut Kementrian Kehutanan (2012) waktu yang ideal untuk melakukan kegiatan pendangiran ini adalah ketika tanaman berumur $1-4$ tahun dan diutamakan pada tanaman yang 
mengalami stagnasi pertumbuhan atau tempat tumbuhnya bertekstur berat dan lahan tidak melalui pengolahan tanah.Pendangiran tanaman dilaksanakan $1-2$ kali dalam satu tahun, tergantung pada tingkat tekstur tanahnya.Makin berat tekstur tanahnya, sebaiknya semakin sering untuk dilakukan pendangiran.tanah yang harus didangir kisarannya $1-3 \mathrm{~m}$ sekeliling tanaman.

\section{d. Penyiangan Gulma}

Menurut Klingman (1964) dalam Zaenudin dan A.B. Santoso (2008) gulma didefinisikan sebagai tumbuhan yang tumbuh di tempat yang tidak dikehendaki. Menurut definisi ini tidak ada batasan yang jelas antara gulma dan tanaman budidaya, dalam arti setiap tanaman yang tumbuh ditempat yang tidak dikehendaki dikategorikan sebagai gulma.

Gangguan gulma terjadi secara terus-menerus, sehingga kegiatan pengendalian gulma harus dilakukan secara rutin (Zaenudin dan Santoso, 2008). Karena hal inilah seluruh petani di Desa Kelungu melakukan penyiangan gulma pada lahan mereka, sedangkan dalam penelitian di Desa Bandar Dalam Kecamatan Sido Mulyo Kabupaten Lampung Selatan dari 38 responden ada 21 responden $(55,3 \%)$ yang selalu melakukannya dan hanya 17 responden $(44,7 \%)$ yang hanya kadang-kadang saja melakukannya. Ini berarti, sebagian besar pemilik hutan rakyat sudah mengetahui bahwa gulma mengganggu pertumbuhan tanaman karena menjadi pesaing tanaman untuk memperoleh cahaya, air dan unsur hara dalam tanah (Pratama dkk., 2015).

Dari $100 \%$ yang melakukan penyiangan gulma sebanyak $70 \%$ petani membersihkan gulma dengan alat sederhana seperti sabit dan koret, dan sebanyak 30\% menggunakan herbisida dengan dosis $50 \mathrm{ml}$ herbisida dicampur dengan air $12 \mathrm{~L}$ dan disemprotkan pada lahan yang ditumbuhi gulma. Waktu pelaksanaan kegiatan penyiangan gulma ini berbeda antara satu petani dengan petani lainnya, kegiatan ini dilakukan dalam kurun waktu 2 minggu sampai 6 bulan sekali. Petani di hutan rakyat Desa Kelungu membersihkan gulma hanya dengan cara mekanis dan kimiawi.

\section{e. Pemangkasan Cabang}

Pemangkasan merupakan salah satu kegiatan pemeliharaan yang banyak dilakukan oleh petani di desa kelungu, karena petani banyak menanam kakao dan kakao merupakan komoditas yang dalam perawatannya memerlukan pemangkasan (Prawoto, 2008). Sebanyak 93\% petani melakukan pemangkasan cabang kegiatan ini dilakukan dalam kurun waktu antara 3 bulan sampai sekali dalam setahun. Pemangkasan cabang dilakukan dengan menggunakan alat yaitu golok, dilakukan dengan memotong cabang-cabang baru yang dapat mengganggu pertumbuhan tanaman.

Secara umum tujuan dari pemangkasan ini untuk menjaga tanaman kakao agar tidak terlalu tinggi dan antar cabangnya tidak saling bersinggungan. Namun lebih dari itu sebenarnya ada banyak manfaat dari kegiatan pemangkasan seperti yang diungkapkan oleh Prawoto (2008) pemangkasan dapat mencegah tanaman kehilangan nutrisi pada saat fase pertumbuhan vegetatifnya (pembentukan daun dan tunas) maupun pada fase pertumbuhan generatif (pembentukan bunga dan biji) sehingga dapat meningkatkan produktivitas tanaman. Selain itu pemangkasan juga dapat membuat tanaman terjaga kelembapannya sehingga tak mudah terserang hama dan penyakit.

\section{f. Pewiwilan}

Pewiwilan yang dilakukan petani di Desa Kelungu merupakan pemeliharaan tanaman berupa pemotongan tunas-tunas muda yang tumbuh pada tanaman. Sebanyak $83 \%$ petani Di Desa Kelungu melakukan pewiwilan pada tanaman yang ada di lahan mereka, pewiwilan dilakukan 
dengan cara memotong tunas-tunas muda yang baru tumbuh dengan menggunakan pisau agar pertumbuhan dari tanaman dapat lebih optimal. Pewiwilan banyak dilakukan pada tanaman Kakao dalam kurun waktu antara 1 minggu sampai 3 bulan sekali. Pewiwilan ini sebaiknya dilakukan pada tanaman yang menghasilkan tunas air cukup banyak (Kementrian Kehutanan, 2012).

\section{g. Penjarangan}

Menurut Kementrian Kehutanan (2012), Penjarangan adalah tindakan pengurangan jumlah batang per satuan luas untukmengatur kembali ruang tumbuh pohon dalam rangka mengurangi persaingan antar pohon. Penjarangan bertujuan memberi ruang tumbuh yang lebih baik atau cukup bagi pohontinggal, memperoleh pohon sehat dan berbatang lurus agar diperoleh hutan dengan massakayu dan kualitas kayu tinggi. Dari pengertian penjarangan diatas dapat diartikan bahwa tanaman yang perlu untuk mendapat penjarangan berupa tanaman berkayu untuk mendapatkan hasil yang maksimal dari segi diameter dan tinggi batang suatu pohon, sedangkan tanaman utama yang ada di Desa Kelungu merupakan tanaman kakao yang kurang perlu dilakukan penjarangan hal ini menyebabkan petani yang melakukan penjarangan sangat sedikit sekali, hanya ada 7\% yang melakukannya.

Penjarangan dilakukan ketika tanaman berumur 5 sampai 10 tahun. Penjarangan dilakukan pada tanaman yang menghasilkan kayu agar tanaman mendapatkan tinggi bebas cabang yang sempurna dan meningkatkan hasil panen kayu. Penjarangan dilakukan dengan cara menebang pohon yang terlalu rapat atau tajuk nya sudah saling bersinggungan dengan menggunakan gergaji mesin.

\section{h. Pengendalian Hama Penyakit}

Hama merupakan organisme pengganggu tumbuhan yang disebabkan oleh serangga, tungau, dan mamalia. Penyakit adalah organisme pengganggu tumbuhan yang disebabkan oleh mikroorganisme berupa jamur, bakteri, atau virus (Sulistyowati, 2008). Status hama dan penyakit yang menyerang daun tanaman hutan pada beberapa tahun yang lalu belum mendapat perhatian serius, karena serangannya masih relatif rendah sehingga belum mendapatkan prioritas penelitian (Anggraeni dan Mindawati, 2011).

Sebanyak 57\% petani melakukan pengendalian hama penyakit pada lahan kebun mereka. hama penyakit dibasmi dengan menggunakan pestisida dengan dosis $50 \mathrm{ml}$ dicampur dengan air sebanyak 12 liter dan disemprotkan pada tanaman yang terkena hama penyakit, pengendalian hama penyakit dilakukan dalam kurun waktu 1 bulan sampai 1 tahun sekali. Meskipun serangan hama penyakit di Hutan Rakyat Desa Kelungu cukup tinggi, namun masih banyak dari para petani yang tidak melakukan tindakan untuk membasmi hama penyakit tersebut, hal ini dikarenakan tidak semua petani melakukan pengendalian hama penyakit sehingga beberapa petani akan merasa percuma jika lahan mereka dibersihkan akan tetapi lahan disebelah lahan mereka tidak dibersihkan, hal ini akan mengundang hama dari lahan tetangga itu akan kembali menyerang lahan petani yang dilakukan pengendalian hama penyakit.

Menurut Sulistyowati (2008) beberapa kegiatan untuk pengendalian hama yaitu pemangkasan, pemupukan, panen sering, sanitasi dan pengendalian hayati dengan memanfaatkan organisme hidupp berupa semut hitam. Sedangkan untuk menanggulangi serangan penyakit kakao perlu dilakukan beberapa kegiatan pemeliharaan yaitu pemupukan, pemberian nauangan, sanitasi, penyemprotan fungisida dan eradiksi (Sukanto, 2008).

Dari serangkaian kegiatan pengendalian hama dan penyakit tanaman di atas, petani belum mempraktekkan hal yang dianjurkan ini pada lahan kebun mereka. Hal ini dikarenakan masih 
minimnya pengetahuan petani terhadap tata cara mengelolah kebun, karena sebagian besar petani mengolah lahan hanya bedasarkan ilmu yang sudah turun temurun dari nenek moyang mereka. selain itu penyuluhan tentang tata cara mengelola lahan yang baik dan benar juga masih sangat jarang mereka dapatkan.

\section{KESIMPULAN DAN SARAN}

\section{KESIMPULAN}

Berdasarkan hasil penelitian yang telah dilakukan, diperoleh kesimpulan sebagai berikut.

1. Dari hasil penelitian Di Desa Kelungu Kecamatan Kotaagung Kabupaten Tanggamus ditemukan 22 spesies, dengan kerapatan tertinggi yaitu Kakao (Theobrema cacao)sebesar 529,17 individu/ha. Untuk fase pohon, kerapatan tertinggi ditempati oleh Durian (Durio zibethinus) yaitu sebesar 73,61 individu/ha.

2. Kegiatan pemeliharaan yang dilakukan oleh petani Di Desa Kelungu meliputi Pemupukan, Penyulaman, Pendangiran, Penyiangan Gulma, Pemangkasan cabang, Pewiwilan, Penjarangan, Pengendalian hama penyakit. Dari 36 petani $60 \%$ diantaranya melakukan pemupukan. 77\% melakukan penyulaman, 77\% melakukan pendangiran, 100\% melakukan penyiangan gulma, 93\% melakukan pemangkasan cabang, 83\% melakukan pewiwilan, 7\% melakukan penjarangan, dan 57\% melakukan pengendalian hama penyakit tanaman.

\section{SARAN}

Berdasarkan hasil penelitian yang telah dilakukan, diperoleh saran sebagai berikut.

1. Sebaiknya semua petani melakukan pengendalian hama penyakit secara menyeluruh agar masalah penyakit di hutan rakyat desa Kelungu dapat teratasi

2. Sebaiknya petani Desa Kelungu menambah tanaman kehutanan pada lahan mereka, karena dari hasil kerapatan, tanaman kehutanan di Desa kelungu masih tergolong sedikit.

3. Diharapkan selanjutnya diadakan penelitian terkait pendapatan dari hasil hutan rakyat Di Desa Kelungu Kecamatan kotaagung Kabupaten Tanggamus. 


\section{DAFTAR PUSTAKA}

Anggraeni. I., Mindawati. N. 2011. Serangan Hama dan Penyakit Pada Gmelina (Gmelina arborea). Di Hutan Rakyat. Bogor. Jurnal Tekno Hutan Tanaman. 4(2) 85-92.

Arikunto, S 2002.Prosedur Penelitian, Suatu Pendekatan Praktek. Jakarta. PT Rineka Cipta.173 p.

Departemen Kehutanan. 1999, Undang Undang Kehutanan No. 41 Tahun 1999.Department Kehutanan. Jakarta. 62 p.

Diniyati, D., dan B. Achmad. 2015. Kontribusi Pendapatan Hasil Hutan Bukan Kayu Pada Usaha Hutan Rakyat Pola Agroforestri di Kabupaten Tasik Malaya. Ciamis. Jurnal Ilmu Kehutanan. 9(1) 23-31.

Indriyanto. 2008. Ekologi Hutan. PT Bumi Aksara. Jakarta. 210 p.

Kelompok Kerja Sanitasi Kota Tanggamus. 2013. Strategi Sanitasi Kabupaten Tanggamus Propinsi Lampung.Badan Perencanaan Pembangunan Daerah Kabupaten Tanggamus. Tanggamus

Kementrian Kehutanan. 2012. Siaran RRI Ke-6 Pemeliharaan Tanaman Hutan.Makassar. Kementrian Kehutanan. 13 p.

Mahendra, A. 2009.Sistem Agroforestri dan Aplikasinya. Graha Ilmu. Yogyakarta.198 p.

Pratama. A. R., S. B.Yuwono., dan R. Hilmato. 2015. Pengelolaan Hutan Rakyat Oleh Kelompok Pemilik Hutan Rakyat di Desa Bandar Dalam Kecamatan Sidomulyo Kabupaten Lampung Selatan.Jurnal Sylva Lestari. 3(2) 99-112.

Prawoto, A. A. 2008. Kakao:Tali Okulasi Kakao. Penebar Swadaya. Depok.363 p.

Pujiyanto, A. Wibawa, dan Winaryo. 2008. Nilai Hara Beberapa Tanaman Penaung Pada Perkebunan Kopi Dan Kakao.Warta Pusat. Jember.

Rizal. A., Nurhaedah, dan E. Hapsari. 2012. Kajian Strategi Optimalisasi Pemanfaatan Lahan Hutan Rakyat Di Provinsi Sulawesi Selatan. Makassar. Jurnal Penelitian Sosial dan Ekonomi Kehutanan. 9(4) 216-228.

Rukmana, H. R., 1996. Prospek Agribisnis dan Budi Daya Nilam.Kanisius.Yogyakarta. 109 p

Sardjono, M. A., T. Djogo, H.S. Arifin, dan N. Wijayanto. 2003. Klasifikasi dan Pola Kombinasi Komponen Agroforestri. Bogor. ICRAF.38 p.

Wijayanto, N., dan A. P. P. Hartoyo. 2015. Biodiversitas Berbasiskan Agroforestry. Bogor. Jurnal Kehutanan IPB. 1(2) 242-246. 